\section{Scientists of the world speak up for equality}

Eight experts give their prescriptions for measures that will help to close the gender gap in nations from China to Sweden.

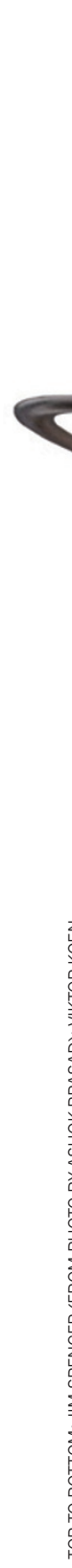

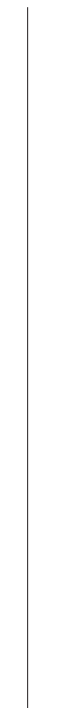

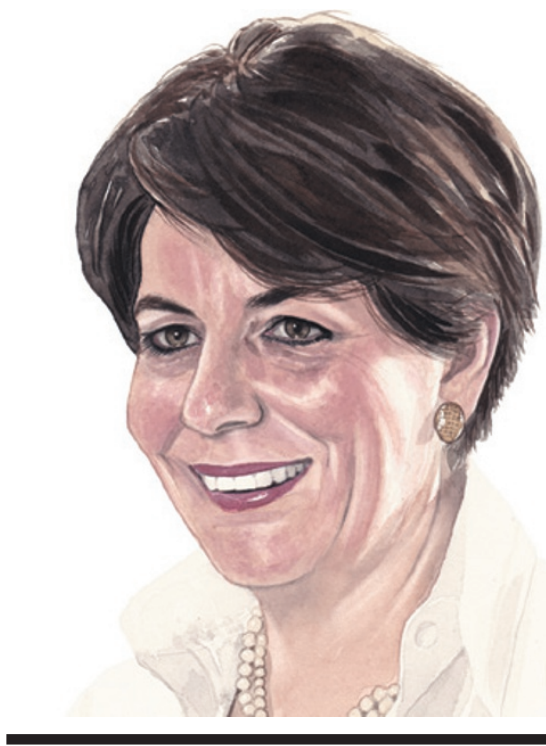

LIHADHAL-GAZALI

Remove social barriers

Clinical geneticist at the United Arab Emirates University in Al-Ain

Just 1\% of Saudi Arabia's researchers were women in 2011, according to the International Labour Organization. This low number is particularly surprising given that $65 \%$ of the nation's bachelor's science degrees go to women. Similar patterns are evident in the rest of the Arab Middle East. Women are clearly interested in science. But many cannot continue their careers because of limiting social attitudes in traditional Arab societies.

The expected role for women graduates included - is housewifery. In some areas, women must ask the permission of the men of the household even to leave their house. Conservative families may not allow their daughters to work in mixed-gender workplaces. To pursue advanced training in research often requires postgraduate study elsewhere. If a woman wishes to do this, the household patriarch may mandate that a male family member accompanies her abroad.

Despite these restrictions, the pool of highly qualified women scientists continues to grow in some Arabic countries. According to the Organisation of Islamic Cooperation in Jeddah, Saudi Arabia, women now represent $19 \%$ of researchers in the occupied Palestinian territories and 22\% in Libya. Few of these women are university presidents,

\begin{tabular}{|l|l|}
\hline & WOMEN IN SCIENCE \\
The gender gap and how to close it \\
nature.com/women
\end{tabular}


directors or department heads.

Having more women in these positions would help to shift cultural expectations. Leading Arab women scientists should continue to get involved in the political life of their countries, where they can be strong advocates for other women scientists. Developments such as the inclusion of leading women academics in the Shura council, Saudi Arabia's highest advisory council (which is now 20\% female), and in the Federal National Council of the United Arab Emirates (22\% female), are steps in the right direction. Highlighting success stories will encourage qualified Arab women to pursue careers in science. Role model and mentoring initiatives are also important. Examples of such programmes include the Stars of Science initiative by the Qatar Foundation for Education, Science and Community Development, and the TechGirls Exchange Program of the US Department of State.

Universities and professional organizations must help to educate the public about what science entails by inviting families to join conferences, careers days or networking events that include presentations of the achievements of women scientists.

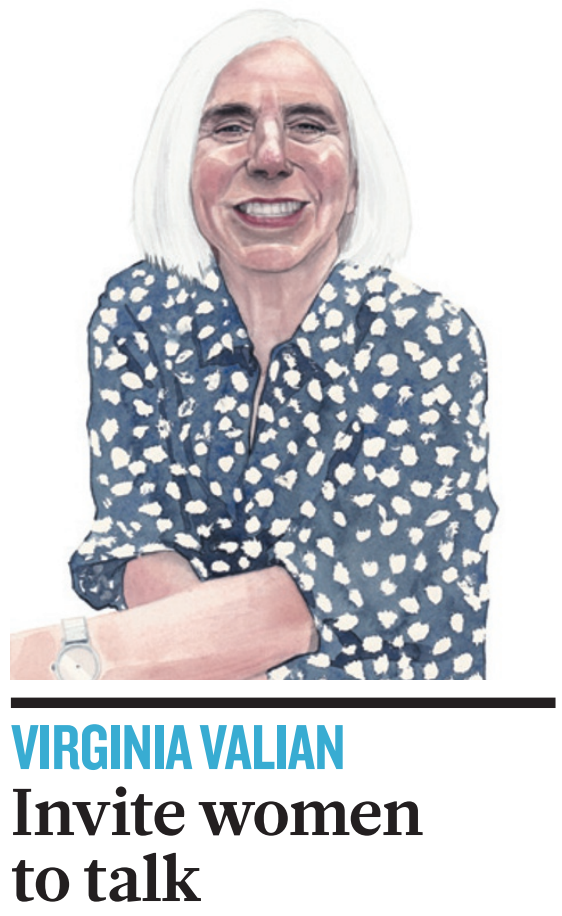

Psychologist at Hunter College and the Graduate Center, City University of New York

In 2003, I was invited to give the keynote speech at an event held annually by the Sigma $\mathrm{Xi}$ scientific-research society to honour scientists' achievements. I was asked to speak about women in science. During dinner, I scanned a list of the event's previous speakers, from 1964 on, to count how many women had given the keynote. Most were listed only by surname and first initial, so between courses, I walked around the room asking people whether they knew anyone on the list. Eventually, I found an older scientist who reviewed the list, recognizing every name, then turned to me with a surprised, rueful smile: in nearly 40 years, I was the only woman to speak at this event. He had heard nearly every lecture but had never noticed that they were all given by men.

At the beginning of my talk, I used that story as an example of how hard it would be for organizers and attendees to detect such a pattern, given only one data point a year. The pattern isn't a product of discrimination or intentional exclusion of women. Rather, few people - men or women - think of women when they picture 'top' scientists who might headline an event.

Are men still disproportionately featured at conferences? Determining an expected number is hard, but it is still relatively rare to find women giving plenary or keynote speeches at conferences. At the American Chemical Society's upcoming spring meeting, for example, all four of the planned plenary speakers are male. That doesn't send an optimistic message to young female chemists. The blog Feminist Philosophers lists nearly 20 recent philosophy conferences - many of which focus on science - featuring only male speakers.

At a language-processing conference I attended recently, I went to 15 or so talks, making note of who asked questions in each one. Women were more likely to ask questions in sessions chaired by women, regardless of the speaker's gender. If that is a general pattern, bringing more women into prominent positions in conferences will increase women's overall participation in scientific discourse. Many organizations strive to include scientists who are from nonEnglish-speaking countries - the same can be done for women.

To that end, my colleague Dan Sperber, a cognitive scientist at the Central European University (CEU) in Budapest, and I have created an online petition (go.nature.com/sj4yed) whose signatories commit to accepting talk invitations only from conferences that have made good-faith efforts to include women. So far, we have more than 450 signatures - but few of them are from senior male scientists, and even fewer are from scientists in the United States.

What counts as a good-faith effort? There is no single prescription, but Sperber and I have adopted a few suggestions from Feminist Philosophers. For one, organizers should seek out women in relevant fields to speak at conferences - and keep looking if the first woman they ask says no. Other examples include extending invitations early so that women have time to make arrangements, and offering child-care services at meeting sites.

But efforts should go beyond the individual. Conference funders should be mindful of gender equity for invited speakers. Similarly, universities should follow the example of the CEU, which now requires that organizers of university-funded events show good-faith efforts to include qualified female speakers (go.nature.com/ym81ws).

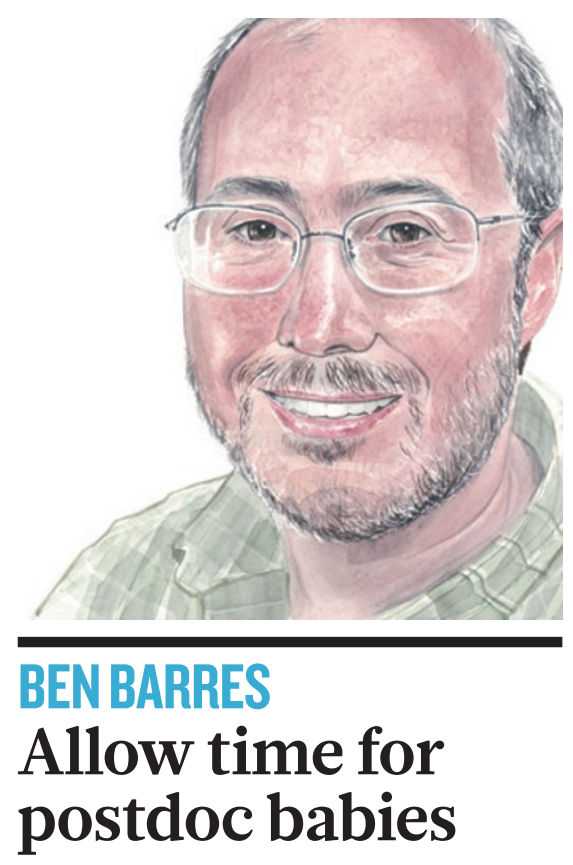

\section{Neurobiologist at Stanford University in California}

Three decades ago, when Nobel laureate Rosalyn Yalow spoke to a women in science group at a major university, her opening statement was: "The primary problem is childcare. Everything else is secondary." Fortunately, many universities now recognize the huge amount of time needed to raise children and help to offset this by providing an extension of 1 year to assistant professors who have a child while seeking tenure. Increasingly, however, scientists are having babies during graduate or postdoctoral training, which together can now total 10 years or more.

I propose that universities modify their tenure-clock extension rules to cover children born at any stage in a career. So even if people already have children when starting out as assistant professors, they should be offered an additional year per child (up to two children, perhaps) to obtain tenure. Even though women typically provide more of the child care than do men, it seems only fair to provide the same extension to men. In the modern world, both parents often work and like to eat dinner with their children (and so cannot write grant applications and papers until midnight). 
This change would remove a persistent, if unintentional, form of discrimination that deters many young scientists, particularly women, from choosing tenure-track jobs, and would increase the chance that those who do will make tenure. At Stanford, our provost routinely grants tenure-clock extensions when requested. Why not just make it the rule at every university?

The main argument against extending tenure clocks is that it might help men more than women, because men may use the extra time to amass papers whereas women use it to raise children. If so, one could argue that this is also true of the tenure-clock extensions already granted. Yet most agree that these have been beneficial to all involved. If universities wish to achieve a more diverse faculty, we must continue to remove obviously discriminatory policies.

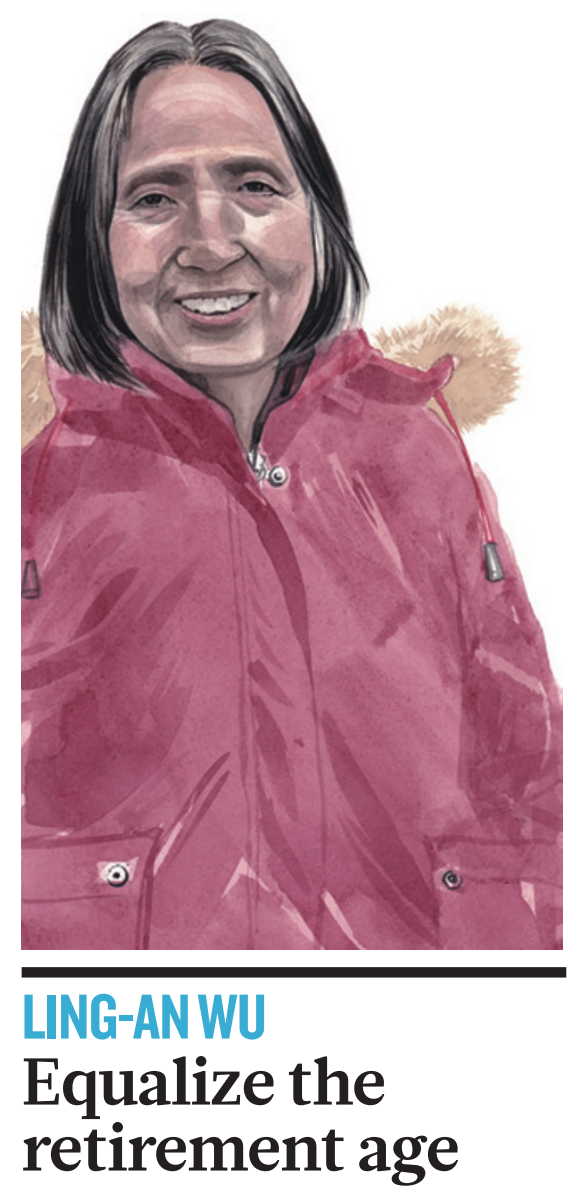

Physicist at the Institute of Physics, Chinese Academy of Sciences, Beijing, China

There are two things that China can and should do to make it easier for women to succeed in science: enforce laws that grant equal opportunities to women in the workplace, and make the retirement age the same for men and women.

In some ways, it is harder to be a woman in science in China today than it was 50 years ago, before the Cultural Revolution. Then, under the socialist system, men and women were given jobs based purely on their performance, so sex ratios were relatively fair. Now that more-capitalist principles infiltrate job placement, it has become more difficult for women to find work. I benefited from the socialist system. After working on a farm for three years, I was assigned a job doing translations at Beijing's Institute of Physics, Chinese Academy of Sciences, because I was fluent in English. This enabled me to go to the United States and obtain a PhD in physics. On returning to the institute with my new skill set, I became a researcher.

Now, women face discriminatory practices that make it harder for them to succeed. For example, in most Chinese institutions, women who are not full professors are required to retire by age 55,5 years before men. The earlier retirement age was originally established to protect women performing manual labour. In science it essentially prevents them from reaching the same career goals as men, particularly if they had to take time off to raise children. In the past, this practice was not compulsory for academia. It was put into effect at the turn of the twentyfirst century to open up positions for young returnees from abroad, who were mostly men. This led to a fast drop in the proportion of women holding lab or department directorships - for example, at my institute, that percentage fell from around $20 \%$ before the 1990 s to $6 \%$ in 2003 . (The proportion of female associate scientists has risen to the original level of $27 \%$, but they still make up only $13 \%$ of the full-scientist ranks.)

Furthermore, bias now plays a major part in job recruitment. Even in academia, I frequently hear faculty members - even women - saying that they would prefer to hire male students. Private companies advertise for men only, or decline to interview female candidates. Although a 1995 law prohibits discrimination by employers based on gender in China, this is often completely disregarded.

Still, the country has made progress. In 2011, the National Natural Science Foundation of China, which oversees the largest source of government funding for fundamental research, raised the age of its young investigators' awards from 35 to 40 for women, to give them time off to raise children. This allows women to compete more fairly with their male counterparts, especially important because the number of day-care centres has plummeted owing to rising costs. Today, Western and old feudal perceptions spread by the media have led to the saying: "It is more worthwhile to find a good husband than a good job." But no one says: "It is more worthwhile to find a good wife than a good job." This saddens me.

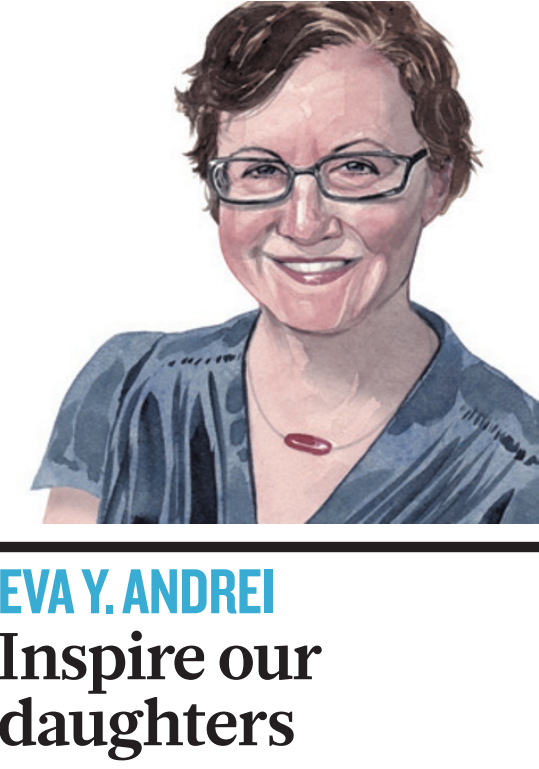

Physicist at Rutgers University in
New Jersey

As a female physicist I am a 'rare bird' - a member of a tiny minority, scarcer than in any other field of science and engineering. Women's representation in physics at major US research universities hovers at about $13 \%$, for many reasons. In my view, these demographics alone make it hard to find female plenary speakers, conference organizers and journal reviewers.

It would be counterproductive to restore the gender balance by burdening the $13 \%$ with more refereeing or committee work. Instead, the solution needs to be sought through inspiring and mentoring highschool girls and undergraduate students.

We must also ask whether girls are less inclined towards physics than boys. Is there something in the discipline or its culture that turns them away? Can this be changed?

I am somewhat heartened to see that the fraction of physics $\mathrm{PhDs}$ earned by women has increased from $2 \%$ in 1966 to $18 \%$ in 2010. The percentage of women faculty members at every rank matches the numbers who graduated in the respective years. Still, we are not there yet, and the decline since 2002 in the number of women earning a bachelor's degree in physics is a further cause for concern.

When I polled my women colleagues, almost all agreed that a dearth of guidance and mentorship early on was the main reason for the lack of female physicists.

The rising tide of women joining the profession will encourage more young women into physics. In the meantime, we should showcase successful female physicists through lectures and prizes, and retain young scientists by offering travel bursaries and by stopping tenure clocks. But to really solve the problem, we must inspire our highschool daughters. 


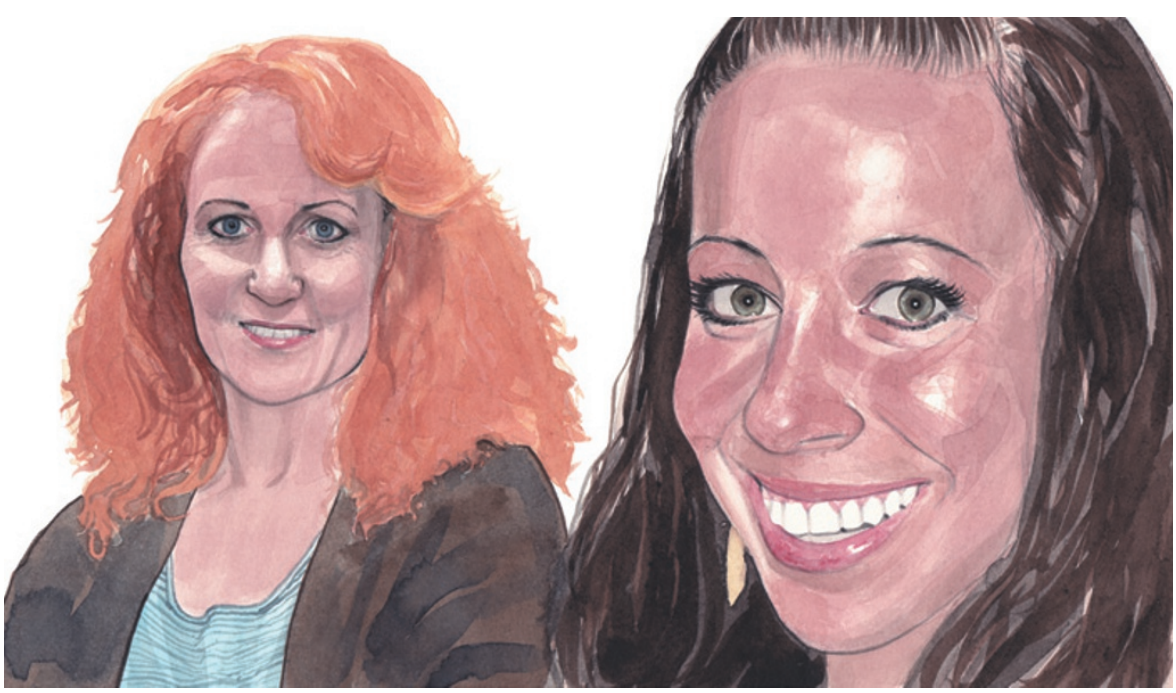

JO HANDELSMAN \& CORINNEMOSS-RACUSIN Institute training to reduce bias

\author{
Microbiologist, and social \\ psychologist, Yale University, \\ New Haven, Connecticut
}

In 2012, we published a study showing that scientists of all ranks and both genders are more likely to hire, mentor and pay more to a 'John' than a 'Jennifer'. Soon afterwards, we were contacted by the office of US congresswoman Louise Slaughter about ways that policy-makers might help to promote gender equity in science.

We proposed that the ethics training now required for students funded by grants from the US National Institutes of Health be expanded to include gender-bias training. Indeed, we feel that all scientists should go through such training. It has been shown that students who undergo diversity training score markedly lower on tests of implicit bias than students who do not (L. A. Rudman et al. J. Pers. Soc. Psychol. 81, 856-868; 2001).

Other approaches can also make a difference - the board game Wages, designed by Stephanie Shields, a psychologist at Pennsylvania State University in University Park, and her colleagues, shows players how subtle disadvantages to women can have enormous cumulative impact on their careers.

Visual priming works too - for example, people who have viewed images of disliked white people and admired African Americans within the past 24 hours are less likely to show automatic pro-white attitudes (N. Dasgupta \& A. G. Greenwald J. Pers. Soc. Psychol. 81, 800-814; 2001).
For more sustained effects, we could paint murals of admired female scientists throughout the halls of universities. A large image of, say, Rosalind Franklin, viewed daily by students in an introductory molecular-biology class, might be even more powerful than explicit instruction on implicit bias. Scientists have agreed on standards and training to ensure proper treatment of animal and human research subjects. The people doing the research are just as important. Striving for equality should be a core aspect of being a scientist.

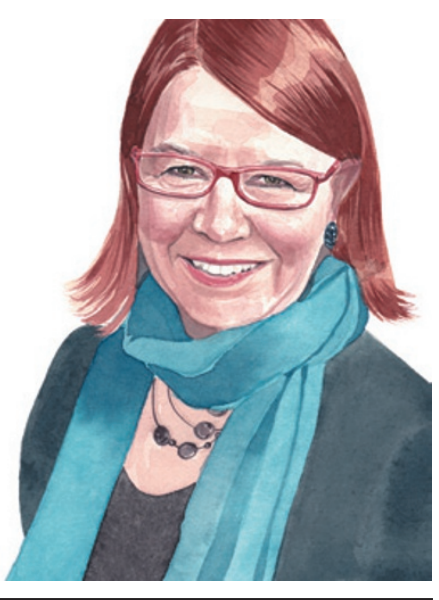

LIISA HUSU

\section{Recognize hidden roadblocks}

Professor of gender studies at the GEXcel Centre of Gender Excellence, Örebro University, Sweden

In researching women in science and academia, I have found that it is not only the things that happen to women - such as recruitment discrimination or belittling remarks - that affect them in pursuing a career in science or that slow their career development. It is also the things that do not happen: what I call 'non-events' (L. Husu Adv. Gender Res. 9, 161-199; 2005).

Non-events are about not being seen, heard, supported, encouraged, taken into account, validated, invited, included, welcomed, greeted or simply asked along. They are a powerful way to subtly discourage, sideline or exclude women from science. A single non-event - for example, failing to cite a relevant report from a female colleague - might seem almost harmless. But the accumulation of such slights over time can have a deep impact.

Non-events can be manifold. Superiors or colleagues might ignore or bypass women's research and performance; fail to invite or welcome them to important informal and formal networks; bypass them for awards, prizes or invitations; fail to give them meritadvancing tasks such as representing the research group in public forums; not ask them to design or participate in scientific meetings, con-
"Non-events are a powerful way to subtly discourage, sideline or exclude women from science." ferences, panels or as keynote speakers; or simply stay silent when it comes to career support, advice and mentoring. Even supposedly small non-events can send a powerful message, such as when a female postdoc publishes a high-profile article that generates no reaction from senior local colleagues, while her male counterpart's parallel article is celebrated with high-fives all round.

Non-events are challenging to recognize and often difficult to respond to. Nothing happened, so why the fuss? Often, nonevents are perceived only in hindsight or when comparing experiences with peers. Learning to recognize various non-events would help women scientists to respond to them, individually or collectively, with confidence and without embarrassment. Anonymous pooling of non-event experiences would be an eye-opener and a good start to understanding how non-events work in various scientific settings.

All scientists - leaders, gatekeepers, rank and file - need to be aware of how they might inadvertently exclude women from crucial collegiality. Monitoring the practices of support, encouragement, inclusion and exclusion in research groups, projects, networks, conferences and science institutions from a gender perspective would be a first step forward. Addressing this issue in management and supervisor training and early-career coaching is key. 